\title{
Disrespectful Maternity Care Experiences Negatively Influence Future Intention to Use Institutional Delivery in Northern Ethiopia
}

\author{
Mengistu Welday Gebremichael ${ }^{*}$ \\ College of Health Sciences, Mekelle University, Ethiopia; \\ Address: P. O. Box 1871, Mekelle University, College of Health Sciences, Mekelle city, Ethiopia \\ Yemane Berhane \\ Addis Continental Institute of Public Health, Addis Ababa, Ethiopia
}

\author{
Alemayehu Worku \\ School of Public Health, Addis Ababa University, Addis Continental Institute of Public Health, Addis Ababa, \\ Ethiopia \\ Araya Abrha Medhanyie \\ College of Health Sciences, Mekelle University, Mekelle, Ethiopia
}

\begin{abstract}
Background

Ethiopia has successfully increased antenatal care coverage substantially, but deliveries attended by skilled providers are still low. Disrespectful and abusive maternity care practices are believed to be among the factors deterring institutional delivery services. However, information on the relationship between women's experience of disrespect and abuse (D\&A) and their future intention to give birth at health facilities is lacking in our context. Therefore, the aim of this study was to examine the association between experiencing disrespectful care and future intention of women to utilize health facilities for delivery.
\end{abstract}

Methods

A cross-sectional study was conducted in Tigray, Ethiopia. Data were collected using a structured questionnaire. Women who had given birth in the health facilities in the twelve months preceding the study were interviewed. D\&A was self reported by the women. Bivariable and multivariable logistic regression models were employed to examine the relationship between future intention of women to use institutional delivery services and their past experience of D and A while receiving maternity care services.

Results

A total of 1,031 women who delivered in health facilities in the last 12 months participated in the study. Of which, $156(15.1 \%)$ reported having experienced two or more types of D\&A while receiving labour and delivery care services. Experiences of D\&A were strongly associated with the intention to use the health facility in future deliveries. The odds of having no intention to use health facilities for future deliveries was extremely high among women who reported they had experienced D\&A ( $\mathrm{aOR}=59.42$; 95\% CI: 30.082, 117.359).

Conclusion

Disrespectful and abusive experiences strongly deterred future use of maternal health services. In order to achieve the desired level of institutional delivery coverage in low- and middle-income countries, attention must be given to improve the manner in which services are offered.

Keywords: Intention to deliver at a health facility, Respectful maternity care, Disrespect and abuse, Tigray, Ethiopia

DOI: $10.7176 / \mathrm{JHMN} / 72-01$

Publication date:March $31^{\text {st }} 2020$

\section{Background}

The main strategy to reduce maternal mortality is to have every delivery attended by skilled personnel (1). In lowand middle-income countries, delivery services are not fully utilized even in settings where services are accessible (2-4). In Ethiopia, efforts to ensure all deliveries are attended by skilled delivery attendants has been ongoing by constructing a large number of health facilities, training health care providers capable of providing maternity/delivery services, and enhancing public education to promote institutional delivery through all available mass media channels (5). Despite accessibility, (antenatal coverage from $27 \%$ in 2000 to $62 \%$ in 2016) and promotion of institutional delivery ( $87 \%$ of women were informed about place of birth), the gap in percentages between the antenatal coverage and institutional delivery coverage is growing (22\% in $2000,24 \%$ in 2011 and $36 \%$ in 2016) (6). 
According to EDHS 2011, participants indicated the reasons for not utilizing institutional delivery services were poor quality of services, believing institutional delivery is not necessary (61.2\%), and not customary (29.5\%). These have been undermining the benefits of institutional delivery and are well-reflected in the low percentage of institutional delivery utilization (7). According to Tigray Regional State, contrary to the above reasons, underachievement in skill-attended deliveries (24\% in 2009; $32 \%$ in 2012 ) was reportedly primarily due to a longstanding tradition of delivering at home and the reluctance of the women to deliver in health facilities (8). Besides the reasons, increased knowledge and awareness does not necessarily lead to use of health service utilization (9).

An essential element of promoting institutional delivery is ensuring providers have good interpersonal skills to treat clients with respect and compassion (10). However, evidence from various low- and middle-income countries indicated that maternal health providers are lacking those skills and the result is either a delay in clients seeking institutional delivery services or choosing to deliver at home (11-14). Poor provider-client interaction barriers (3) and disrespectful care $(11,13,15)$ were reported as contributors for low utilization of institutional delivery.

Studies reported varying level of disrespectful and abusive care in low- and middle-income countries; $20 \%$ in Kenya and Tanzania $(16,17)$, and $98 \%$ in Nigeria (18). There are very few studies on respectful maternity care conducted in Ethiopia. Two institution-based studies have shown a prevalence with a wide range $(36.0 \%$ versus $78.6 \%)$ of D\&A mothers experiencing at least one type of D\&A during their care $(19,20)$. Non-dignified service, physical abuse, and detention in facilities are the most frequent types of D\&A reported in those settings (21).

Although disrespectful and abusive maternity care practices are known to be common, empirical evidence that related it with future intention of service use in low-income countries is still scarce. Therefore, the objective of this study was to assess the association between women's future intention to use institutional delivery services and their experience of disrespectful and abusive maternity care during their last pregnancy.

\section{Methods}

This study was conducted from August 14 to September 3, 2015 in the Tigray region, northern Ethiopia. The Tigray region, with a population of 5.1 million, is administratively divided into 7 Zones (22). In the region, there are 668 health posts, 218 health centers, and 11 primary hospitals, 16 general hospitals and 1 specialized hospital with the total health service coverage of $96 \%$. According to the Regional Health Bureau, antenatal care coverage was $100 \%$, deliveries attended by skilled personnel was $60 \%$, and postnatal care coverage was $69.6 \%$ (22). Good local leadership, dedication of health professionals, strengthening community health programs, improved referral and ambulance services, and opening maternity homes around health facilities were the reasons cited for improved maternal health service coverage in the region (8).

This study utilized a community based cross-sectional study design. Study subjects were women who delivered in health facilities in the twelve months preceding the study. In this study, we use the phrase health facility to cover both health centers and hospitals. In Ethiopia the majority of women give birth at a health center. This study was part of a big study on "Respectiful Maternity Care: Women's Experiencce of Disrepsect and Abuse, and Future Intention of Instituional Delivery Utilization in Tigray, Ethiopia" (23). The sample size was estimated based on a single population proportion formula. By assuming a $4 \%$ margin of error, $95 \%$ confidence level, and at least $50 \%$ of women expected to change their intention of future usage of institutional delivery multiplied by 1.5 design effect (DEFF), about 1,000 women who gave birth in the year of the study were required to estimate the rate of women's intention to have an institutional delivery in the future.

A multistage sampling procedure was applied to select study participants for the study. Six districts of Tigray region (3 rural and 3 urban districts) were selected. Then nine "kebeles" (six kebeles from rural and three kebele from urban) were selected randomly. The "kebeles" (used as clusters) are the lowest administrative units in Ethiopia. Eligible women living in the selected clusters were studied.

Data were collected by trained data collectors using a structured questionnaire in the months of August and Septmber, 2015. Data collectors used a translated questionnaire. The English version was translated into the local language Tigrigna. The translation was done by two experts and translated back into English by another set of experts. The tool was reviewed by local experts for content validity and later pre-tested before the main survey. Interviews were conducted face-to-face at household level. During the study period, completed questionnaires were checked every day by trained field supervisors and the principal investigator.

D\&A was measured using a 14 item scale. The scale includes: 1)shouting 2)scolding/insulting 3)discouraging/ became negative 4)ignoring my request for assistance/help 5)not telling the necessary information before/during a procedure 6)discussing my private health information in public 7)sharing my health information with others 8)let me lay in unhygienic bed/couch 9)felt shame for being exposed naked to others unnecessarily 10)movement restriction for long time 11)procedure/s done without being adequately informed 12)left me alone unattended 13)hitting/slapping/pushing 14)any other experience that you do not want to mention. Women who reported more than one item of D\&A positively were considered disrespected or abused, the remaining were classified as not disrespected or abused. Intention to use institutional delivery in the future was assessed by asking 
the women whether they intend to deliver again in a health facility or not. Responses were categorized into two after excluding those who reported having no intention to give birth again because they already have the desired number of children. Those who intend to go to the health facility for delivery were categorized as 'having intention to deliver in health facility in the future, and the remaining were categorized as 'no intention to deliver in a health facility in the future'. The latter includes preference to deliver at home and seeking assistance from traditional birth attendants. The content validity of the tools was determined by submitting the tool to five experts. The experts were selected from public health, obstetric, sociology, law and psychology departments of Mekelle University. The selection of experts depended on the closeness of the study, experience and interest of the experts towards the study. The content was validated by the experts on a judgment basis. They were given the option of "agree" or "disagree" for each item in terms of relevance, accuracy, and appropriateness in relation to the problem of the study, objective and purpose of the study. For the option of "disagreement" or "agreement" a column of suggestion was given that would be for modification or radical change of the items.

Data were kept in a safe place for storage and processing. Data were entered using Epidata version 3.1, Data were cleaned and then transferred to SPSS version 20. The electronic data were password protected and shared only to the study team. As the outcome was dichotomous, we used logistic regression model to assess the associations between the outcome and the predictor variables, and an association was considered statistically significant at alpha 0.05 levels with $95 \%$ confidence interval. The goodness of fit of the model was checked using Hosmer and Lemeshow test and found to be good. Variables were included in multivariable logistic regression model if their p-value were either found to be less than 0.25 in bivariable logistic regression or important variable of the study.

The study subjects were given information about the objective of the study and their permission was sought. Women who visited maternity units for services were informed about the nature of the study. And informed consent was obtained from each participant before proceeding further. Talks with the village head, chief or community leaders of the villages were held to create smooth working relations in those villages. The study was scheduled and arranged as much as possible to not interfere with daily activities or invade the privacy of the participants in any way. A written contract in Tigrigna was required for verification; for those who were illiterate, a thumbprint was used for signing.

\section{Results}

Out of 1,031 women interviewed, the majority (80.2\%) of the women were between the age of 20 and 34 years of age. About $63 \%$ of them were rural residents, and $34 \%$ had no formal education. About $17 \%$ of women reported generating their own income (Table 1).

Of the total 1,031 women, $864(84 \%)$ of them reported that a health centre was the nearest health facility for birthing, and $96(9.3 \%)$ of them considered distance as a potential barrier to utilize delivery services. Additionally, almost $6 \%$ of them felt not at ease using a health facility for giving birth. Out of the total study subjects, 931 $(90.5 \%)$ spent less than 12 hours in labour in the maternity ward of the health facility (Table 2 ).

Of women utilizing labour and delivery care services, $11 \%$ of them reported that, they were shouted at, about $10 \%$ of them were scolded/insulted, and $7.3 \%$ of them reported that their requests for help were ignored. About $7 \%$ of the women reported that health care providers did not share necessary information related to the procedure they were receiving. Six percent of the study subjects reported that they were left alone unattended while they were in labour and delivery, and $5.9 \%$ of the women reported that health care providers had performed procedures without informing them adequately. About $5 \%$ of women reported that they were discouraged or care providers became negative towards them. A few women (4\%) reported that they were lay in an unhygienic bed/couch, and $3.7 \%$ reported that their movement was restricted for a long time. Around $2 \%$ of women reported that they felt shame for being exposed naked to others unnecessarily.

Fifteen percent of the study participants reported more than one types of D\&A during their most recent experience of giving birth at a facility. Out of the total, one in ten women expressed having no intention to use a health facility for future deliveries (Table 2 ).

Multivariable logistic regression model was used to examine the factors associated with women's future intention of using health facilities for delivery. Table 3 shows the results of multivariable analysis. In this analysis, residence, feeling at ease to visit health facilities, duration of labour at health facility, level of D\&A experienced during labour and delivery were significantly associated with intention of future usage of institutional delivery.

Urban dwellers and women who reported that they felt not at ease to visit health facilities were about four times more likely to intend not to use health facility to give birth in the future than their counterparts respectively (Fig.1). Women who spent 12 hours or more in labour in the health facility were about 4 times more likely not to intend to go to health facilities for future delivery than those who spent less than 12 hours in labour. Experiences of D\&A were strongly associated with intention not to use a health facility for a future delivery. Women who were abused were almost 60 times more likely not to intend to go to a health facility for future delivery than those women who were not abused (Fig.1; Table 3). 


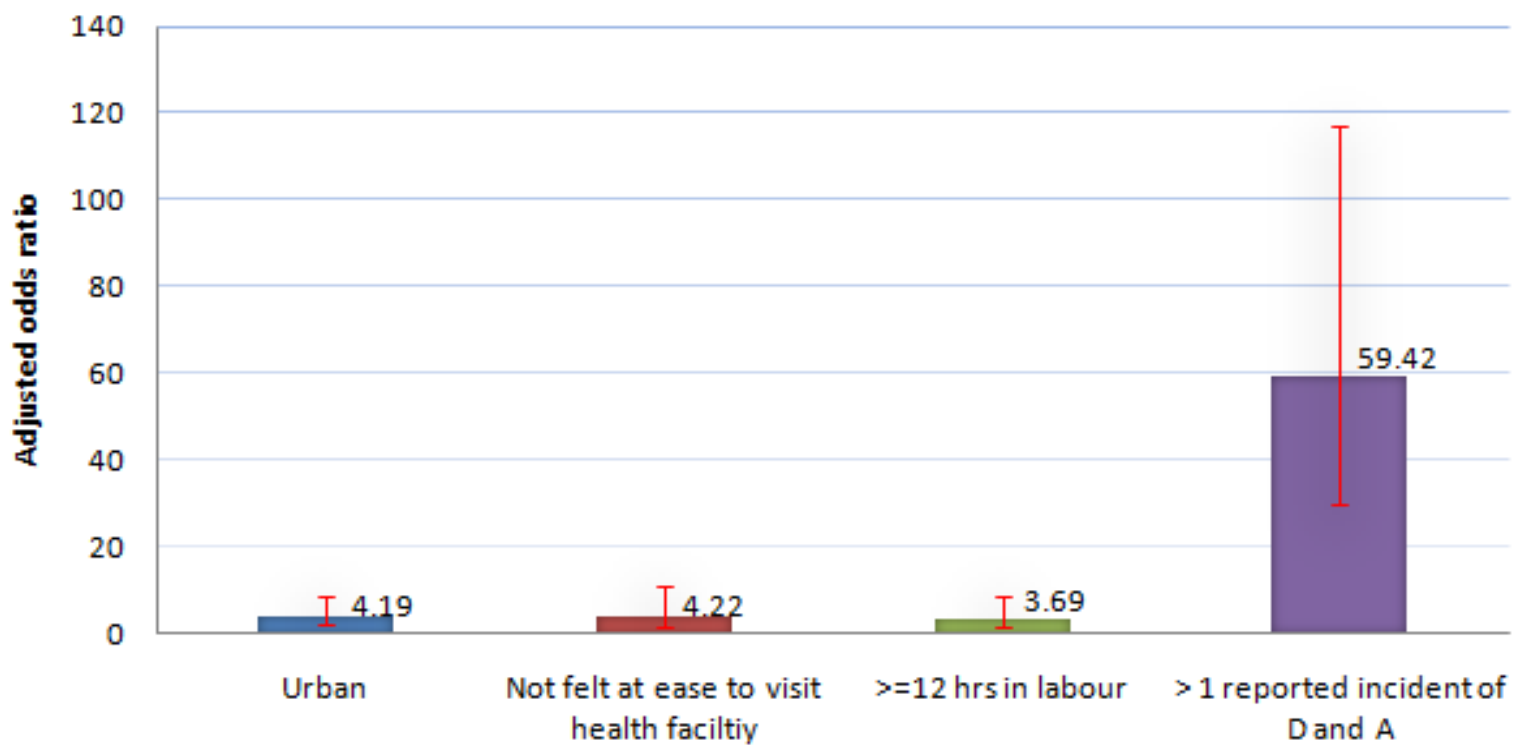

Fig. 1: Associated exposure variables with women's intention not to utilize institutional delivery services in Tigray, Ethiopia, 2015

\section{Discussion}

In our study, women's future intention to deliver at a health facility is associated significantly with experience of D\&A during maternity service utilization. In addition, significant associations were found between residence, not feeling at ease to go to a health facility, duration of labour, and women's intention of future usage of institutional delivery.

About $10 \%$ of the study participants had reported no future intention to use health facilities for giving birth, perhaps due to D\&A as reported by Bohren (24). According to Zahourek, intention is purposeful (25) and prompts action. If a woman does not intend to utilize a health facility for a future delivery that creates a challenge in promoting the skilled care services. Merely making health services accessible does not sustain increased usage of institutional deliveries, as accessibility does not fully guarantee service utilization (26). Service accessibility may attract and enroll new users but might not be sufficient to retain women as continuous users of the service. Several studies have shown that even women who are aware of the benefits of institutional delivery refrain from using health facilities for delivery because of perceived or experienced low quality services, including non-dignified maternity care (27-29). Such practice could be substantiated by a theory of planned behavior as it is reflected in its basic assumption that performing a certain behavior depends on the intention to perform that behavior (30), and similarly intention is influenced by other factors and either by negative or positive experience or perception.

In this study, women's intentions of not to use institutional delivery service in the future was significantly higher among women subjected to disrespectful and abusive care. When women experience D\&A during labour and delivery, they may consider alternatives that can help them minimize or avoid such distressful encounters (15). Mistreatment of a woman contradicts the principle of Safe Motherhood to render woman and newborn friendly childbirth services (31). In addition, women's intention not to go to health facilities for childbirth is significantly high among urban dwellers, and women who did not feel at ease to go to the health facility. It is believed that women with education and urban dwellers know their rights and expressed their feelings more freely and may take action intentionally. It is known that women refuse care from health providers who treat them poorly, even if these providers are capable of preventing or managing obstetric or newborn complications (26). Globally, lack of friendly and culturally sensitive health services has curtailed service use, although accessibility has improved substantially by constructing new health facilities $(32,33)$.

Furthermore, women who experienced longer labour duration (more than 12 hours) in the labour ward tends not to utilize institutional delivery in the future. As duration of labour increases, so does the length and frequency of contact between the woman and care provider/s, which could be stressful for both parties (34). Hence the level of D\&A by stressed care providers may increase, or a woman experiencing stress could have a decreased tolerance to such events. Experience of D\&A could be influenced from the individual (professional or woman) or from the system/environment (35). An incident of D\&A may be perceived by women differently at different times. Women who encountered care providers that were not kind and understanding also reported dissatisfaction with the care they received $(36,37)$. In this study, the quantity of incidents of disrespect and abuse during labour and delivery is similar to other study findings conducted in Kenya, Ethiopia and Tanzania $(16,38,39)$, but it is very low 
compared to other findings from Nigeria (98\%) (18). Asefa and his colleagues in Ethiopia found $16 \%$ of selfreported D\&A (20). D\&A becomes a common practice because of the lack of local accountability of services and lack of action taken against professionals who commit the malpractice (40). The study indicated that interventions focusing on increasing service accessibility or coverage alone would not necessarily help to reach maternal and newborn mortality reduction targets (26).

As respectful maternity care (RMC) is the main essence of quality maternity care not icing on the cake, strategies ensuring practices RMC in a woman's whole care or all the time during the care. This could be done with emphasizing to prevent any incident of D \& A: 1)understanding the individual woman's need/s or preference/s through small scale quantitative and qualitative researches 2)creating mechanisms to handle and manage women's complaint/s if they have any experience of mistreatment/s 3)redressing mechanism to those who are affected emotionally/psychologically/physically due to providers' treatment 4)in-service training on the needs of RMC as a core area of providers' practice 5)incorporating RMC in curricula of health science students as part of pre-service training

Strengths

This community-based study included participants interviewed outside heath facilities at household level and this gave them more freedom to express their feelings and report positive and negative experiences without fear. It also helped to eliminate social desirability bias (41).

\section{Limitations}

We acknowledge recall bias as a possible limitation. Though we limited the recall period to one year, this might still be considered too long to recall details of incidents of disrespect and abuse. Though the tool was developed and considered all the domains of D\&A reported by Bowser and Hill (42), and contextualized to the area and study subjects, it was not validated. The study did not also consider the immediate adverse outcomes and consequences of disrespectful and abusive experiences either to the women or their babies.

\section{Conclusions}

In conclusion, future intention to use institutional delivery services is significantly influenced by the women's experience of D\&A. Efforts to increase institutional delivery in low- and middle income countries need to promote respectful maternity care in all maternity related services and it is important to establish and strengthen accountability mechanisms where women can report if they experience D\&A during their use of the health services.

\section{Declarations}

\section{Ethics approval and consent to participate}

Ethical clearance was obtained from Mekelle University IRB (Institutional Review Board). The study subjects provided written consent to participate in the study after receiving information about the purpose of the study, risks and benefits, and their rights. Study subjects were also assured of privacy during the interview and confidentiality of information.

\section{Consent for publication}

Not applicable.

\section{Availability of data and materials}

IRB does not allow authors to transfer data to third party.

\section{Competing interests}

The authors declare that they have no competing interests.

Funding

Mekelle University supported this study financially, and African Population and Health Research Centre (APHRC) too at the grant number 2016-2018 ADF 011.

\section{Authors' contributions}

Study conceived and designed by: MWG, YB AW. Study performed: MWG YB AW AAM. Data analysis and write up: MWG YB AW AAM. Wrote the paper: MWG YB AW AAM. Critically reviewed for intellectual content and approved the final manuscript: MWG YB AW AAM.

\section{Acknowledgements}

The authors would like to thank Mekelle University for financial and technical support. We are grateful to Addis Continental Institute of Public Health for the support it provided for this study. This work was also partially funded by an African Doctoral Dissertation Research Fellowship (ADDRF) award offered by African Population and Health Research Centre (APHRC). Special thanks to the Tigray Regional Health Bureau and its District Health Offices for facilitating the fieldwork. We also thank all women who participated in the study. At last, we would be grateful to University of Michigan for the proof reading services rendered on free, and IHI for offering me a mentorship support.

\footnotetext{
Author details

${ }^{1}$ Mekelle University, College of Health Sciences, Mekelle, Ethiopia, ${ }^{2}$ Addis Continental Institute of Public Health,
} 
Addis Ababa, Ethiopia, ${ }^{2,3}$ School of Public Health, Addis Ababa University, Addis Ababa, Ethiopia

\section{References}

1. WHO. Making pregnancy safer : the critical role of the skilled attendant: a joint statement by WHO, ICM and FIGO [Internet]. 2004 Available http://www.unscn.org/layout/modules/resources/files/Making_pregnancy_safer_the_critical_role.pdf

2. WHO. Antenatal care in developing countries: promises, achievements and missed opportunities: an analysis of trends, levels and differentials, 1990-2001. [Internet]. 2003. Available from: http://apps.who.int/iris/bitstream/10665/42784/1/9241590947.pdf

3. Bowser D, Hill K. Exploring Evidence for Disrespect and Abuse in Facility-Based Childbirth Report of a Landscape Analysis. Harvard Sch Public Heal Univ Res Co, LLC [Internet]. 2010;1-57. Available from: http://www.urc-chs.com/uploads/resourceFiles/Live/RespectfulCareatBirth9-20-101Final.pdf

4. Cotter K, Hawken M, Temmerman M. Low Use of Skilled Attendants' Delivery Services in Rural Kenya. 2006;24(4):467-71.

5. Federal Ministry of Health of Ethiopia. Health Sector Transformation Plan. 2015.

6. Central Statistical Agency (Ethiopia) and ICF International. Ethiopia demographic and health survey 2016. Addis Ababa, Ethiopia: Central Statistical Agency and ICF International. 2017.

7. Central Statistical Agency (Ethiopia) and ICF International. Ethiopia demographic and health survey 2011. Addis Ababa, Ethiopia: Central Statistical Agency and ICF International. 2012.

8. Tigray Regional Heath Bureau. Annual Profile 2004 EFY. The Government of Tigray National Regional State, Bureau of Health; Ethiopia. Mekelle; 2012.

9. The Change project. Maternal Survival: Improving Access to Skilled Care. A Behavior Change Approach [Internet]. 2005. Available from: www.changeproject.org

10. Dao B. Respectful maternity care: A clinician's perspectives. In: Presentation in Rome from October 7-12, 2012 [Internet]. 2012. Available from: http://www.scribd.com/doc/110376766/Respectful-Maternity-CareA-Clinician\%25E2\%2580\%2599s-Perspectives-BDao-FIGO2012

11. Yakong VN, Rush KL, Bassett-smith J, Bottorff JL, Robinson C. Women's experiences of seeking reproductive health care in rural Ghana: challenges for maternal health service utilization. 2010;

12. Kruk ME, Paczkowski M, Mbaruku G, Pinho H De, Galea S. Women's Preferences for Place of Delivery in Rural Tanzania : A Population-Based Discrete Choice Experiment. 2015;99(9):1666-72.

13. Kilaru A, Karachiwala B, Matthews Z. Women' s experience of the quality of care in institutional delivery : evidence from a prospective study in rural south India. 2012;6(Suppl 1):1-2.

14. Fagbamigbe AF, Idemudia ES. Barriers to antenatal care use in Nigeria : evidences from non-users and implications for maternal health programming. ???; 2015;1-10.

15. Kruk ME, Mbaruku G, McCord CW, Moran M, Rockers PC, Galea S. Bypassing primary care facilities for childbirth: A population-based study in rural Tanzania. Health Policy Plan. 2009;24(4):279-88.

16. Abuya T, Warren CE, Miller N, Njuki R, Ndwiga C, Maranga A, et al. Exploring the Prevalence of Disrespect and Abuse during Childbirth in Kenya...: EBSCOhost. PLoS One. 2015;10(4):1-13.

17. Kruk M, Kujawski S, Mbaruku G, Ramsey K, Moyo W, Freedm. Disrespectful and abusive treatment during facility delivery in Tanzania: a facility and community survey. Health Policy Plan. 2014;33(1):1-8.

18. Okafor II, Ugwu EO, Obi SN. Disrespect and abuse during facility-based childbirth in a low-income country. Int J Gynecol Obstet [Internet]. International Federation of Gynecology and Obstetrics; 2015;128(2):110-3. Available from: http://dx.doi.org/10.1016/j.ijgo.2014.08.015

19. Sheferaw ED, Bazant E, Gibson H, Fenta HB, Ayalew F, Belay TB, et al. Respectful maternity care in Ethiopian public health facilities. Reprod Health [Internet]. Reproductive Health; 2017;14(1):60. Available from: http://reproductive-health-journal.biomedcentral.com/articles/10.1186/s12978-017-0323-4

20. Asefa A, Bekele D. Status of respectful and non-abusive care during facility-based childbirth in a hospital and health centers in Addis Ababa, Ethiopia. Reprod Health [Internet]. 2015;12(1):33. Available from: http://www.reproductive-health-journal.com/content/12/1/33

21. Ishola F, Owolabi O, Filippi V. Disrespect and abuse of women during childbirth in Nigeria: A systematic review. PLoS One [Internet]. 2017;12(3):e0174084. Available from: http://dx.plos.org/10.1371/journal.pone.0174084

22. Tigray Regional Health Bureau. Nine years performance report on selected core indicators; 1998-2006 EFY. Mekelle, Ethiopia: Dayo printing; 2014.

23. Gebremichael MW, Worku A, Medhanyie AA, Berhane Y. Mothers 'experience of disrespect and abuse during maternity care in northern Ethiopia. Glob Health Action [Internet]. Taylor \& Francis; 2018;11(0). Available from: https://doi.org/10.1080/16549716.2018.1465215

24. Bohren MA, Hunter EC, Munthe-kaas HM, Souza JP, Vogel JP. Facilitators and barriers to facility-based delivery in low- and middle-income countries : a qualitative evidence synthesis. 2014;1-17. 
25. Zahourek, R. P., \& Larkin DM. Consciousness, intentionality, and community: Unitary perspectives and research. Nurs Sci Q. 2009;22(1):15-22.

26. Austin A, Langer A, Salam RA, Lassi ZS, Das JK, Bhutta ZA. Approaches to improve the quality of maternal and newborn health care : an overview of the evidence. 2014;11(Suppl 2):1-9.

27. Gebrehiwot T, San Sebastian M, Edin K, Goicolea I. Health workers' perceptions of facilitators of and barriers to institutional delivery in Tigray, Northern Ethiopia. BMC Pregnancy Childbirth [Internet]. 2014;14(1):no pagination. Available from: http:/www.biomedcentral.com/14712393/14/137\%5Cnhttp://ovidsp.ovid.com/ovidweb.cgi?T=JS\&PAGE=reference\&D=emed12\&NEWS=N\& $\mathrm{AN}=2014287523$

28. Matthews Z, Ramakrishna J, Mahendra S, Kilaru A GS. Birth rights and rituals in rural south India: care seeking in the intrapartum period. J Biosoc Sci. 2005;37(4):387-411.

29. Sayih A. Factors determining choice of delivery place among women's of child bearing age in DegaDamot Woreda, west Gojjam zone, Amhara Regional State, Ethiopia. 2014.

30. Ajzen I. The Theory of Planned Behavior. Organ Behav Hum Decis Process. 1991;50:179-211.

31. FIGO Committee on Safe Motherhood and Newborn Healthcare. Mother and Newborn Friendly Birthing Facility. 2014;(February):9.

32. McMahon S a, George AS, Chebet JJ, Mosha IH, Mpembeni RN, Winch PJ. Experiences of and responses to disrespectful maternity care and abuse during childbirth; a qualitative study with women and men in Morogoro Region, Tanzania. BMC Pregnancy Childbirth [Internet]. 2014;14(1):268. Available from: http://www.ncbi.nlm.nih.gov/pubmed/25112432

33. International Federation of Gynecology and Obstetrics, International Confederation of Midwives, White Ribbon Alliance, International Pediatric Association, World Health Organization. Mother-baby friendly birthing facilities. Int J Gynecol Obstet [Internet]. Elsevier B.V.; 2015;128(2):95-9. Available from: http://linkinghub.elsevier.com/retrieve/pii/S0020729214005451

34. Abushaikha L, Sheil EP. Labor Stress and Nursing Support: How do They Relate? J Int Womens Stud [Internet]. 2006;7(4):198-208. Available from: http://vc.bridgew.edu/jiws/vol7/iss4/13

35. Changole J, Bandawe C, Makanani B, Nkanaunena K, Taulo F, Malunga E, et al. Patients' satisfaction with reproductive health services at Gogo Chatinkha Maternity Unit, Queen Elizabeth Central Hospital, Blantyre, Malawi. (Special Section: Reproductive health.). Malawi Med J [Internet]. 2010;22(1):5-9. Available from: http://ovidsp.ovid.com/ovidweb.cgi?T=JS\&CSC $=$ Y\&NEWS $=$ N\&PAGE $=$ fulltext\&D $=$ cagh\&AN=20113158 733\%5Cnhttp://shtmsfx.hosted.exlibrisgroup.com/lshtm?sid=OVID:caghdb\&id=pmid:\&id=doi:\&issn=\&is bn $=\&$ volume $=22 \&$ issue $=1 \&$ spage $=5 \&$ pages $=5-9 \&$ date $=2010 \&$ title $=$ Malawi + Medical + Journa

36. Brown S LJ. Satisfaction with care in labor and birth: a survey of 790 Australian women. Birth. 1994;21(1):413.

37. Small R, Roth C, Raval M, Shafiei T, Korfker D, Heaman M. City Research Online Immigrant and nonimmigrant women' $\mathrm{s}$ experiences of maternity care : a systematic and comparative review of studies in five countries. 2014;14.

38. The last Ten Kilometers (L10K) project. Disrespect and abuse during facility-based childbirth in four PHCUs in two regions of Ethiopia - Baseline Study Findings [Internet]. 2014. Available from: https://www.semanticscholar.org/paper/Disrespect-and-abuse-during-facility-based-infour/3f5145440beceff6e35e3c5e3170b402aabf0dd9?tab=citations

39. Sando D, Ratcliffe H, McDonald K, Spiegelman D, Lyatuu G, Mwanyika-Sando M, et al. The prevalence of disrespect and abuse during facility-based childbirth in urban Tanzania. BMC Pregnancy Childbirth [Internet]. BMC Pregnancy and Childbirth; 2016;16(1):1-10. Available from: http://dx.doi.org/10.1186/s12884-016$1019-4$

40. Jewkes R, Abrahams N, Mvo z. why do nurses abuse patients ? reflections from south african obstetric services. Soc Sci Med. 1998;47(11):1781-95.

41. D'Ambruoso L, Abbey M, Hussein J. Please understand when I cry out in pain: women's accounts of maternity services during labour and delivery in Ghana. BMC Public Health. 2005;5:140.

42. Bowser D, Hill K. Exploring Evidence for Disrespect and Abuse in Facility-Based Childbirth Report of a Landscape Analysis. Harvard Sch Public Heal Univ Res Co, LLC [Internet]. 2010;1-57. Available from: https://www.harpnet.org/wp-content/uploads/2018/02/10.-Exploring-Evidence-for-Disrespect-and-AbuseLandscape-Analysis.pdf 
Table 1: Socio-demographic and economic characteristics of the study subject $(\mathrm{N}=1031)$

\begin{tabular}{|c|c|c|c|}
\hline Variable & Category & Number & Percent \\
\hline \multirow[t]{2}{*}{ Residence } & Urban & 384 & 37.2 \\
\hline & Rural & 647 & 62.8 \\
\hline \multirow[t]{5}{*}{ Age in years } & $<20$ & 69 & 6.7 \\
\hline & $20-24$ & 304 & 29.5 \\
\hline & $25-29$ & 352 & 34.1 \\
\hline & $30-34$ & 171 & 16.6 \\
\hline & 35 and above & 135 & 13.1 \\
\hline \multirow[t]{2}{*}{ Age at marriage } & $<20$ years & 695 & 68.5 \\
\hline & 20-34 years & 320 & 31.5 \\
\hline \multirow[t]{3}{*}{ Education } & Illiterate & 346 & 33.6 \\
\hline & $1-10$ (three cycles) & 578 & 56.1 \\
\hline & Pre-College-University and above & 107 & 10.4 \\
\hline \multirow[t]{2}{*}{ Head of the household } & Husband & 973 & 94.4 \\
\hline & Wife & 58 & 5.6 \\
\hline \multirow[t]{3}{*}{ Husband's education } & Illiterate & 267 & 27.6 \\
\hline & $1-10$ (three cycles) & 491 & 50.7 \\
\hline & Pre-College-University and above & 210 & 21.7 \\
\hline \multirow[t]{2}{*}{ Generating her own income } & Yes & 168 & 16.6 \\
\hline & No & 843 & 83.4 \\
\hline \multirow[t]{3}{*}{ Wealth index } & Low & 519 & 50.4 \\
\hline & Medium & 362 & 35.1 \\
\hline & High & 149 & 14.5 \\
\hline
\end{tabular}

Table 2: Maternal Service related factors $(\mathrm{N}=1031)$

\begin{tabular}{|c|c|c|c|}
\hline Variable & Category & Number & Percent \\
\hline \multirow[t]{2}{*}{ Type of the nearest health facility } & Health Center & 864 & 84.0 \\
\hline & Hospital & 165 & 16.0 \\
\hline \multirow{2}{*}{$\begin{array}{l}\text { Distance considered as a potential barrier to using } \\
\text { delivery services }\end{array}$} & Yes & 96 & 9.3 \\
\hline & No & 933 & 90.7 \\
\hline \multirow{2}{*}{$\begin{array}{l}\text { Transportation mentioned as a potential barrier to } \\
\text { using delivery services }\end{array}$} & Yes & 88 & 8.6 \\
\hline & No & 941 & 91.4 \\
\hline \multirow[t]{2}{*}{ Feels not at ease using health facilities for delivery } & Disagree & 972 & 94.3 \\
\hline & Agree & 58 & 5.6 \\
\hline \multirow[t]{2}{*}{ Number of ANC visits during the last pregnancy } & Less than four & 323 & 31.6 \\
\hline & Four and above & 698 & 68.4 \\
\hline \multirow{2}{*}{$\begin{array}{l}\text { Duration of labour during the last institutional } \\
\text { delivery }\end{array}$} & $<12$ hours & 931 & 90.5 \\
\hline & $>=12$ hours & 98 & 9.5 \\
\hline \multirow[t]{2}{*}{ Reported D\&A during labour and delivery } & One incident or none & 875 & 84.9 \\
\hline & More than one incidents & 156 & 15.1 \\
\hline \multirow[t]{2}{*}{ Reported Service satisfaction } & Yes & 882 & 85.5 \\
\hline & No & 149 & 14.5 \\
\hline \multirow{3}{*}{$\begin{array}{l}\text { Intention to use } \\
\text { Health facility for future birthing }\end{array}$} & Yes & 926 & 89.8 \\
\hline & No & 102 & 9.9 \\
\hline & $\begin{array}{l}\text { No intention of having } \\
\text { another child }\end{array}$ & 3 & 0.3 \\
\hline
\end{tabular}


Table 3: Crude and adjusted odds ratios of intention of future usage of institutional delivery and certain independent variables $(\mathrm{N}=1,031)$

\begin{tabular}{|c|c|c|c|c|}
\hline \multirow[t]{2}{*}{ Variables } & $\begin{array}{l}\text { In } \\
\text { to use heal } \\
\text { birthing in th }\end{array}$ & for & \multirow[t]{2}{*}{$\begin{array}{r}\text { Crude Odds } \\
\text { Ratio and 95\% CI }\end{array}$} & \multirow[t]{2}{*}{$\begin{array}{r}\text { Adjusted Odds } \\
\text { Ratio and 95\% CI }\end{array}$} \\
\hline & No & Yes & & \\
\hline \multicolumn{5}{|l|}{ Residence } \\
\hline \multirow{2}{*}{$\begin{array}{l}\text { Urban } \\
\text { Rural }\end{array}$} & 64 & 317 & $3.23(2.118,4.943)^{*}$ & $4.19(1.969,8.911)^{*}$ \\
\hline & 38 & 609 & 1 & 1 \\
\hline \multirow{3}{*}{$\begin{array}{l}\text { Age in years } \\
<20 \\
20-34 \\
>=35\end{array}$} & 3 & 66 & $0.63(0.165,2.412)$ & $0.76(0.105,5.450)$ \\
\hline & 90 & 735 & $1.70(0.835,3.463)$ & $0.94(0.338,2.624)$ \\
\hline & 9 & 125 & 1 & 1 \\
\hline \multirow{3}{*}{$\begin{array}{l}\text { Education } \\
\text { Illiterate } \\
1-10 \text { (Three cycles) } \\
\text { Pre-College-University } \\
\text { \&above }\end{array}$} & 21 & 325 & 1 & 1 \\
\hline & 63 & 512 & $1.90(1.140,3.181)^{*}$ & $0.79(0.305,2.058)$ \\
\hline & 18 & 89 & $3.13(1.599,6.128)^{*}$ & $1.36(0.349,5.319)$ \\
\hline \multirow{3}{*}{$\begin{array}{l}\text { Husband's education } \\
\text { Illiterate } \\
1-10 \text { (three cycles) } \\
\text { Pre-College-University } \\
\& \text { above }\end{array}$} & 18 & 249 & 1 & 1 \\
\hline & 49 & 439 & $1.54(0.880,2.709)$ & $0.87(0.350,2.169)$ \\
\hline & 26 & 184 & $1.96(1.041,3.672)^{*}$ & $0.72(0.225,2.295)$ \\
\hline \multicolumn{5}{|l|}{$\begin{array}{l}\text { Generating her own } \\
\text { income }\end{array}$} \\
\hline \multirow{2}{*}{$\begin{array}{l}\text { Yes } \\
\text { No }\end{array}$} & 29 & 138 & $2.28(1.427,3.641)^{*}$ & $1.70(0.779,3.705)$ \\
\hline & 71 & 770 & 1 & 1 \\
\hline \multirow{2}{*}{$\begin{array}{l}\text { Age at marriage } \\
<20 \text { years } \\
20-34 \text { years } \\
\end{array}$} & 54 & 640 & 1 & 1 \\
\hline & 47 & 271 & $2.06(1.356,3.116)^{*}$ & $0.53(0.259,1.083)$ \\
\hline \multirow{2}{*}{$\begin{array}{l}\text { Head of the household } \\
\text { Husband } \\
\text { Wife }\end{array}$} & 91 & 879 & 1 & 1 \\
\hline & 11 & 47 & $2.26(1.133,4.512)^{*}$ & $0.83(0.158,4.348)$ \\
\hline \multirow[t]{2}{*}{$\begin{array}{l}\text { Not felt at ease to visit } \\
\text { institution } \\
\text { Disagree }\end{array}$} & 82 & 888 & 1 & 1 \\
\hline & 20 & 37 & $\begin{array}{r}5.85(3.248 \\
10.551)^{*}\end{array}$ & $4.22(1.630,10.903)^{*}$ \\
\hline \multicolumn{5}{|l|}{$\begin{array}{l}\text { Nearest Health } \\
\text { Institution }\end{array}$} \\
\hline \multirow{2}{*}{$\begin{array}{l}\text { Health Center } \\
\text { Hospital }\end{array}$} & 71 & 791 & 1 & 1 \\
\hline & 31 & 133 & $2.60(1.639,4.114)^{*}$ & $1.76(0.816,3.774)$ \\
\hline \multirow{2}{*}{$\begin{array}{l}\text { Distance as a barrier } \\
\text { Yes } \\
\text { No }\end{array}$} & 6 & 90 & $0.58(0.247,1.359)$ & $1.31(0.400,4.304)$ \\
\hline & 96 & 834 & 1 & 1 \\
\hline \multirow{2}{*}{$\begin{array}{l}\text { Duration of labour at } \\
\text { institution } \\
<12 \text { hour } \\
>=12 \text { hours }\end{array}$} & 77 & 851 & 1 & 1 \\
\hline & 24 & 74 & $3.58(2.139,6.006)^{*}$ & $3.69(1.568,8.690)^{*}$ \\
\hline \multirow{2}{*}{$\begin{array}{l}\text { Reported D\&A during } \\
\text { labour \& delivery } \\
\text { One incident or none } \\
\text { More than one incidents }\end{array}$} & 17 & 857 & 1 & 1 \\
\hline & 85 & 69 & $\begin{array}{r}62.10 \\
(34.924,110.429)^{*}\end{array}$ & $59.42(30.082,117.359)^{*}$ \\
\hline
\end{tabular}

